\title{
The Effect of Social Warmth on Green Consumption
}

\author{
Jialing Yang \\ School of Management, Jinan University, Guangzhou, China \\ Email: jnuyjl@126.com
}

How to cite this paper: Yang, J.L. (2019) The Effect of Social Warmth on Green Consumption. American Journal of Industrial and Business Management, 9, 482-490. https://doi.org/10.4236/ajibm.2019.93032

Received: February 13, 2019

Accepted: March 11, 2019

Published: March 14, 2019

Copyright $\odot 2019$ by author(s) and Scientific Research Publishing Inc. This work is licensed under the Creative Commons Attribution International License (CC BY 4.0).

http://creativecommons.org/licenses/by/4.0/

\begin{abstract}
With the increasing emphasis on resources and environmental issues, green consumption is becoming more and more important. Green consumption is affected by social factors. In the social context, there are more studies on social unfriendly aspects, such as social exclusion, but neglect socially friendly situations-social warmth. Therefore, this study will explore the mechanism of the impact of social warmth on green consumption. The conclusion of study is that social warmth has a significant impact on the willingness to purchase green products, and environmental self-responsibility plays a mediating role.
\end{abstract}

\section{Keywords}

Social Warmth, Environmental Self-Responsibility, Resource Scarcity, Green Consumption

\section{Introduction}

With the resources and environmental issues become increasingly prominent, corporate investment in environmental protection and development of green products continues to increase; consumer awareness of green consumption is also rising. At the production level, many enterprises increase the development of green products. For example, Procter \& Gamble has adopted a new technology in its laundry Tide purclean, which produces $65 \%$ of its ingredients from plants and recyclable materials. At the consumption level, Ali Research Institute released the "2017 China Green Consumer Report", pointing out that the number of green consumers exceeds 110 million, accounting for $20 \%$ of Taobao's active users. Although the number of green consumers continues to grow, compared with traditional products, the proportion of green products transactions is still small, and non-green consumption is still the mainstream consumption. It 
can be seen that how to promote consumers to buy green products will greatly help enterprise.

Green consumer behavior is a kind of altruistic behavior [1], influenced by social factors, that is, the behavior or state of existence of other individuals can affect consumers. But the social situation is a multi-faceted environment, and consumers will be affected by different social context perceptions. Therefore, it is necessary to further study the research on the willingness to purchase green products in different social situations. In social contexts, there are many studies on social unfriendly aspects, such as social exclusion [2] [3], but neglect socially friendly situations-social warmth.

Social warmth is the experience of feeling loved by and connected to other people. In daily life, we will be warmed by parents, teachers, friends, and marketers in the shopping environment. So, does the warmth of others affect consumers' purchasing decisions?

Social warmth promotes positive social connections, such as trust, sharing [4]. But how does social warming promote positive social connections? There are few studies on its mechanism. There are relatively few studies related to other fields, especially in the field of consumption, which needs to be further explored. In this paper, the study of social warmth extends to the consumption field. Therefore, this paper aims to study green consumption, explore the effect of social warmth on green consumption, and the mediator of environmental self-responsibility. The conclusions of this paper help to deepen the understanding of social factors on green consumption, and also provide implications for enterprises.

\section{Literature Review}

\subsection{Green Consumption}

Green products, are also known as "Environmentally friendly products", "Environmentally compatible products". Lin and Chang (2012) [5] pointed out that green products are those that do not harm the environment and does not contain potentially harmful ingredients. This study focuses on the altruistic nature of green products.

Green products are typical representatives of prosocial products. On the one hand, green consumption is an altruistic behavior [1]. Consumers must not only consider the value that consumer behavior brings to themselves, but also consider consumer behavior to others. On the other hand, green consumption can be understood as a special self-control balance. Consumers need to face the dilemma of their own interests and social interests when they purchase green products. Social factors emphasize the role of others in the willingness to purchase consumer products. Because green consumption is a pro-social behavior, it is influenced by social factors.

\subsection{Social Warmth}

Social warmth is the experience of feeling loved by and connected to other 
people. At the beginning of the birth, the individual was originally in the warm, protected environment in the mother's womb. From these early interactions, warmth may have sent a signal that social connections and concerns [6]. Some scholars believe that individuals can use social warmth as an indicator of social resources [7].

On the one hand, social warmth leads to sharing behavior. Participants conducted virtual economic trust games after touching cold or hot items. The results showed that the warm experience would enhance interpersonal trust, that is, subjects who touched hot items were more willing to invest money in strangers. On the other hand, social warmth leads to trust behavior. Williams and Bargh (2008) [8] first conducted an empirical study of the relationship between social warmth and physical warmth. The study found that participants with hand-held thermal therapy pads tended to choose gifts that could be given to friends, while those with cold therapy pads were more likely to choose gifts for themselves. The study shows that physical warmth can promote an individual's perception of warmth in interpersonal relationships.

\subsection{Environmental Self-Responsibility}

Self-accountability refers to the desire of consumers to practice environmental self-standards. When environmental self-regulation is prominent, consumers are more likely to adhere to these standards and assess or adjust their actions according to these criteria [9]. The meaning of environmental self-standards is that individuals will consider the environment, resources and other factors in their daily consumption, and have a series of guidelines for their ability to do harm to the environment and the moral bottom line.

Relevant research on environmental self-responsibility mainly demonstrates the impact of environmental self-responsibility on environmentally friendly behavior. On the one hand, environmental protection self-responsibility promotes environmental protection activities. Schultz (1999) [10] found that when activating personal norms or social norms as self-standards, the activation of moral components in self-criteria, individuals need to be aware of the impact of their actions on others or the environment, or feel that they have moral responsibility for the environment. Consumers generate higher environmental self-responsibility. On the other hand, environmental self-responsibility encourages consumers to choose environmentally friendly consumption. The study found that environmental self-responsibility affects consumers' demands. When consumers have a strong environmental self-responsibility, they stimulate consumers to expect guilty feelings because they do not purchase green products. Consumers are more active in products that are environmental than self-interested [9].

\section{Hypothesis}

Social warmth is the experience of feeling loved by and connected to other people. After individuals are warmed by society, they believe that there is a fu- 
sion between self and others [11]. The link between social warmth and pro-social awareness is the result of lifelong over-learning, which is driven by evolutionary tendencies [8]. Therefore, when individuals are warmed by society, they will promote more social connections, so that the development of individual self is more affected by others and enhances pro-social awareness.

Green products are typical representatives of pro-social products [1]. Green consumption is affected by social factors. In a social context, others' behavior is particularly important for individual [12]. As an important social factor, social warmth encourages individuals to feel caring and hopes to maintain a better social connection, thereby enhancing prosocial awareness and guiding consumers to influence pro-social behavior (e.g. green consumption). Thus:

$\mathrm{H1}$ : Social warmth will have a positive effect on the purchase likelihood of green products.

Environmental self-responsibility can promote the generation of environmentally friendly behaviors, but an important premise is the activation of moral components in self-standards, that is, individuals need to be aware of the impact of their actions on others or the environment, or feel their responsibility that they are moral to the environment. The start-up theory emphasizes external stimulus factors. Consumers' participation in green consumption may come from launching environmental protection-related ideas, protecting environmental dynamics and goals, or feeling more environmentally friendly to increase consumers' green consumption propensity [13].

When consumers perceive social warmth, they act more consideration connect with others, so social warmth can promote positive emotional warmth and interpersonal behavior, such as trust, sharing [14]. These generated emotions, behaviors and morality are closely related, which also shows that the degree of social warmth enhances the individual's moral level, and social warmth has the function of moral activation. This is also because after perceiving social warmth, the individual will more consider the "correct social standards", improve the moral self-awareness, and increase the moral motives that aim at social interests. The environmental self-responsibility is the individual's moral awareness of the environment. Then, after perceiving social warmth, the environmental self-standard becomes prominent and a higher self-responsibility is generated. Further, environmental self-responsibility as a source of motivation for green consumption can promote consumers' willingness to purchase green. Thus:

$\mathrm{H} 2$ : Environmental self-responsibility plays a mediator role on the influence process of $\mathrm{H} 1$.

\section{Research Methodology}

Single-factor inter-group experimental design was used in the experiment. Participants were randomly assigned to group A and group B. Among them, group $A$ is the social warmth group, group $B$ is the control group. The dependent variable is the willingness to purchase green products. 
The experiment was completed online and in the university library. $100 \mathrm{col}-$ lege students and online testers participated in the experiment. In the returned questionnaire, 7 participants were incompletely completed. After removing 7 participants who did not complete the experiment as required, a total of 93 valid questionnaires were retrieved (44 in the social warming group; 49 in the control group). Among them, 43 boys, accounting for $46.2 \%$, 50 girls, accounting for $53.8 \%$; 44 undergraduates, accounting for $47.3 \%, 49$ graduate students, accounting for $52.7 \%$; the average age of participants was 21.56 years. Since the demographic information such as education and income has no significant impact on the experimental results, the subsequent experimental analysis no longer includes such data.

First, the participants will complete the task of recalling writing. In this experiment, the social warmth was manipulated by the recall method, and the subjects were asked to complete the writing task according to the instruction. Then, the subjects answered the social warm control test items along a 7-point scale (1 $=$ very disagree, $7=$ very agree) .

Second, the participants will fill out a questionnaire about environmental self-responsibility. Participants answered the relevant items along a 7-point scale ( 1 = very disagree, 7 = strongly agree), and the measurements refer to Peloza [9].

Third, ask the participants to fill in the willingness to purchase green products, and ask the participants to fill in their personal information, including gender, age, education and other information. The selection of green product experimental materials for this experiment is based on the study by Griskevicius (2010), allowing participants to read the information on the two backpacks $S$ and the backpack E. The two backpacks are the same size and the same price, but they differ in material and craftsmanship, and are highlighted in the feature description. Among them, the backpack S emphasizes the functionality and style, and the backpack emphasizes environmental protection. After reading the product information, the participants completed the green product manipulation test.

\section{Data Analysis}

An ANOVA on social warmth revealed that participants in the social warmth condition indicated warmer $(\mathrm{M}=5.92, \mathrm{SD}=1.15)$ than did those in the control condition $(\mathrm{M}=4.55, \mathrm{SD}=1.60 ; \mathrm{F}(1,91)=20.91, \mathrm{P}<0.001)$. The single-sample $\mathrm{t}$-test was used for the analysis. As expected, compared to the non-green product $(\mathrm{M}=2.34, \mathrm{SD}=1.42, \mathrm{t}(92)=15.94, \mathrm{df}=92, \mathrm{P}<0.001)$, the green product was associated with being more green $(\mathrm{M}=6.41, \mathrm{SD}=1.00, \mathrm{t}(92)=61.64, \mathrm{df}=92, \mathrm{P}$ $<0.001)$. It shows that the subjects can effectively distinguish the experimental materials, and the green consumption situation of the experiment is successfully manipulated.

Taking social warmth as the independent variable and the willingness to purchase green products as the dependent variable, one-way analysis of variance 
showed that the main effect of social warming on the willingness to purchase green products was significant $(\mathrm{F}(1,91)=6.63, \mathrm{P}<0.05)$. Compared with the control group $(\mathrm{M}=3.03, \mathrm{SD}=1.13)$, the participants in the social warming group $(\mathrm{M}=3.74, \mathrm{SD}=1.51)$ were more willing to spend green consumption, indicating that social warmth would lead consumers to preference for green products, support H1.

In order to test the mediating effect of environmental self-responsibility, we use the three-step median regression method proposed by Wen Zhonglin et al. (2004) for analysis.

The first step is to use the consumer's willingness to purchase as the dependent variable and the social warmth as the independent variable. The regression result shows that the adjusted $\mathrm{R}$ square is 0.058 , the model is significant $(\mathrm{P}=$ $0.012<0.05)$ and the social warmth has a significant regression on the purchase intention $(\beta=-0.261, \mathrm{P}=0.012)$ and social warmth affects consumers' willingness to purchase green products.

In the second step, the environmental self-responsibility is the dependent variable, and the social warmth is the independent variable. The regression results show that the adjusted $\mathrm{R}$-square is 0.050 , the model is significant, $\mathrm{P}=$ 0.018 , and the social warmth returns to the environmental self-responsibility significantly, $\beta=-0.245, \mathrm{P}=0.018$, social warmth affects consumers' environmental self-responsibility.

In the third step, the consumer's willingness to purchase is the dependent variable, and the social warmth and environmental self-responsibility are the independent variables. The regression results show that the adjusted $\mathrm{R}$-square is 0.090 , the model is significant, $\mathrm{P}=0.005$, and the environmental self-responsibility returns to the purchase intention. Significantly, $\beta=0.210, \mathrm{P}=0.044$, environmental self-responsibility has a significant impact on purchase intention. Social warmth has a significant return to purchase intention, $\beta=-0.209, \mathrm{P}=0.044$. Compared with Model 1, the significance is reduced, indicating that environmental self-responsibility has a mediating effect on social warmth and purchase intention, and is a partial intermediary. The results of specific regression analysis are shown in Table 1 . Thus, environmental self-responsibility plays a mediator role, support $\mathrm{H} 2$.

\section{Conclusions}

\subsection{Theoretical Contributions}

For green consumption research, previous studies have focused on the impact of social factors such as impression management motivation and normative beliefs on the willingness to purchase green products. In this study, social warmth is used as an entry point to explore the influence of another social factor on the tendency of green product purchase behavior, and enrich the research on the traits or existence status of other individuals in the social context. For the study of social warmth, previous studies have mostly promoted social warmth from 
Table 1. Regression.

\begin{tabular}{|c|c|c|c|c|c|c|}
\hline \multirow{3}{*}{ Variable } & \multirow{2}{*}{\multicolumn{2}{|c|}{$\begin{array}{c}\text { Model } 1 \\
\begin{array}{l}\text { Green purchase } \\
\text { consumption }\end{array}\end{array}$}} & \multicolumn{2}{|c|}{ Model 2} & \multicolumn{2}{|c|}{ Model 3} \\
\hline & & & $\begin{array}{l}\text { Envi } \\
\text { self-re }\end{array}$ & $\begin{array}{l}\text { ental } \\
\text { sibility }\end{array}$ & $\begin{array}{r}\text { Greer } \\
\text { cons }\end{array}$ & $\begin{array}{l}\text { hase } \\
\text { tion }\end{array}$ \\
\hline & $\beta$ & $\mathrm{P}$ & $\beta$ & $\mathrm{P}$ & $\beta$ & $\mathrm{P}$ \\
\hline Social warmth & -0.261 & 0.012 & -0.245 & 0.018 & -0.209 & 0.044 \\
\hline $\begin{array}{c}\text { Environmental } \\
\text { self-responsibility }\end{array}$ & & & & & 0.210 & 0.044 \\
\hline Adjusted R-square & & & & & & \\
\hline $\mathrm{P}$ & & & & & & \\
\hline
\end{tabular}

physical warmth, social warmth as a mechanism of physical warmth, and thus on other behaviors. In this paper, the study of social warmth extends to the consumption field, and explores the mechanism of social warmth affecting consumer behavior. The introduction of green consumption theme not only more concretely relates the relationship between social warmth and pro-social behavior, but also has research on social warmth.

\subsection{Practical Contributions}

The destruction of the ecological environment is becoming more and more serious. Coupled with the implementation of the government's sustainable development strategy and the awareness of consumers' green consumption, the pressure on environmental protection is increasing, and the huge green consumer market brings unlimited business opportunities. The marketing strategy of enterprises has turned to green marketing in line with the international trend. Green marketing is of great significance to the development of the company. From the perspective of marketing practice, firstly, for enterprises, social warmth can be applied to propaganda strategy and staff management, providing new ideas for the marketing and management of enterprises. Green products are altruistic and egoistic. For altruistic green products, enterprises can use moral materials to promote more social and environmental benefits. In the physical environment, the service quality should be publicized to employees, so that consumers can feel the care and social contact of service personnel, create a good social warmth, stimulate consumers' self-consciousness and perception, and guide consumers to buy products. For self-interested green products, we should avoid excessive use of social materials and pay more attention to personal interests. Second, for the government and non-profit organizations, they should enhance social warmth, make consumers more aware of the correctness of social goals, consider social norms, and promote pro-social consumption behavior.

\subsection{Research Limitations}

There are some limitations of the study in the discussion section. Firstly, the all participants are students; this will result in sample limitations. Secondly, this 
study only selected backpack as test items. It will result in test items limitations. Finally, the study is finished in the laboratory. Thus, there is no real shopping environment and product display. It maybe results in the lack of experiment validity.

\section{Conflicts of Interest}

The author declares no conflicts of interest regarding the publication of this paper.

\section{References}

[1] Griskevicius, V., Tybur, J.M. and Van den Bergh, B. (2010) Going Green to Be Seen: Status, Reputation, and Conspicuous Conservation. Journal of Personality and Social Psychology, 98, 392. https://doi.org/10.1037/a0017346

[2] Jiang, H., Yang, Z., Sun, P. and Xu, M. (2018) When Does Social Exclusion Increase or Decrease Food Self-Regulation? The Moderating Role of Time Orientation. Journal of Consumer Behaviour, 17, 34-46. https://doi.org/10.1002/cb.1684

[3] Twenge, J.M., Baumeister, R.F., Dewall, C.N., Ciarocco, N.J. and Bartels, J.M. (2007) Social Exclusion Decreases Prosocial Behavior. Journal of Personality and Social Psychology, 92, 56-66. https://doi.org/10.1037/0022-3514.92.1.56

[4] Ijzerman, H., Karremans, J.C.T.M., Thomsen, L. and Schubert, T.W. (2013) Caring for sharing. How attachment styles modulate communal cues of Physical Warmth. Social Psychology, 44, 160-166. https://doi.org/10.1027/1864-9335/a000142

[5] Lin, Y.C. and Chang, C.C.A. (2012) Double Standard: The Role of Environmental Consciousness in Green Product Usage. Journal of Marketing, 76, 125-134. https://doi.org/10.1509/jm.11.0264

[6] Panksepp, J., Nelson, E. and Bekkedal, M. (2010) Brain Systems for the Mediation of Social Separation-Distress and Social-Reward Evolutionary Antecedents and Neuropeptide Intermediaries. Annals of the New York Academy of Sciences, 807, 78-100. https://doi.org/10.1111/j.1749-6632.1997.tb51914.x

[7] Ijzerman, H. and Semin, G.R. (2010) Temperature Perceptions as a Ground for Social Proximity. Journal of Experimental Social Psychology, 46, 867-873. https://doi.org/10.1016/j.jesp.2010.07.015

[8] Williams, L.E. and Bargh, J.A. (2008) Experiencing Physical Warmth Promotes Interpersonal Warmth. Science, 322, 606-607. https://doi.org/10.1126/science.1162548

[9] Peloza, J., White, K. and Shang, J. (2013) Good and Guilt-Free: The Role of Self-Accountability in Influencing Preferences for Products with Ethical Attributes. Journal of Marketing, 77, 104-119. https://doi.org/10.1509/jm.11.0454

[10] Schultz, P.W. (1999) Changing Behavior with Normative Feedback Interventions: A Field Experiment on Curbside Recycling. Basic and Applied Social Psychology, 21, 25-36. https://doi.org/10.1207/s15324834basp2101_3

[11] IJzerman, H. and Semin, G.R. (2009) The Thermometer of Social Relations: Mapping Social Proximity on Temperature. Psychological Science, 20, 1214-1220. https://doi.org/10.1111/j.1467-9280.2009.02434.x

[12] Luo, X. (2007) How Does Shopping with Others Influence Impulsive Purchasing? Journal of Consumer Psychology, 15, 288-294. https://doi.org/10.1207/s15327663jcp1504_3

[13] Wheeler, S.C., Demarree, K.G. and Petty, R.E. (2014) Understanding Prime-to-Behavior 
Effects: Insights from the Active-Self Account. Social Cognition, 32, 109-123. https://doi.org/10.1521/soco.2014.32.supp.109

[14] Kang, Y., Williams, L.E., Clark, M.S., Gray, J.R. and Bargh, J.A. (2011) Physical Temperature Effects on Trust Behavior: The Role of Insula. Social Cognitive and Affective Neuroscience, 6, 507-515. https://doi.org/10.1093/scan/nsq077 